\title{
Potential analysis of a new removable insulation system
}

\author{
Thibault Pflug a,b,*, Bruno Bueno ${ }^{\mathrm{a}}$, Monica Siroux ${ }^{\mathrm{b}}$, Tilmann E. Kuhn ${ }^{\mathrm{a}}$ \\ a Fraunhofer Institute for Solar Energy Systems ISE, Heidenhofstraße 2, 79110 Freiburg, Germany \\ ${ }^{\mathrm{b}}$ ICube UMR7357, Université de Strasbourg, INSA Strasbourg, 24 boulevard de la Victoire, 67084 Strasbourg Cedex, France
}

\section{A R T I C L E I N F O}

\section{Article history:}

Received 2 February 2017

Received in revised form 30 June 2017

Accepted 16 August 2017

Available online 22 August 2017

\section{Keywords:}

Switchable insulation

Switchable U-value

Switchable window

Building heating and cooling energy

demand

Experimental investigation

Hot plate measurement

U-value

ISO15099

Control strategies

Potential analysis

\begin{abstract}
A B S T R A C T
In this paper, the potential of a facade element with switchable $U$-value and $g$-value is investigated. This new switchable facade element consists of a series of air-filled cavities separated by opaque films, that can be rolled up or down between two fixed layers, thus switching the thermal and optical properties from a thermally insulating state to a conducting state. A first prototype has been built and measured in the insulating state and the properties of the facade element have been optimized using a theoretical analysis at the facade level. The $U$-value can be switched from a value of $0.35 \mathrm{~W} \mathrm{~m}^{-2} \mathrm{~K}^{-1}$ in the insulating state to a value of $2.7 \mathrm{~W} \mathrm{~m}^{-2} \mathrm{~K}^{-1}$ in the conducting state. Building energy simulations using EnergyPlus showed that the sum of the heating and cooling demands could be reduced by about $30 \%$ with the switchable insulation used as a window application or in front of an opaque massive wall. Even better performance could be achieved by reducing the frame or edge losses. The influence of the thermal mass, and finally the influence of orientation on the overall performance are also investigated and were found to be non-negligible.
\end{abstract}

(C) 2017 Elsevier B.V. All rights reserved.

\section{Introduction}

The level of insulation of new buildings has increased significantly in recent years due to more restrictive regulations on building energy demand. For example, the French thermal regulation for new building [1] requires a maximum of $50 \mathrm{kWh} \mathrm{m}^{-2} \mathrm{yr}^{-1}$ of primary energy demand (modulated depending on location), while the Passivhaus [2] and Minergie [3] regulations require a maximal heating demand of $15 \mathrm{kWh} \mathrm{m}^{-2} \mathrm{yr}^{-1}$ and $38 \mathrm{kWh} \mathrm{m}^{-2} \mathrm{yr}^{-1}$, respectively. In addition, the Passivhaus and Minergie regulations require for example a maximum $U$-value for the opaque parts of $0.15 \mathrm{~W} \mathrm{~m}^{-2} \mathrm{~K}^{-1}$. However, increasing the thermal insulation of the building skin, leading to very low $U$-values, can prevent reductions in the building heating and cooling demand that could be achieved if the insulation could be deactivated temporarily. Additional insulation can, for example, slow down the nightly cooling process in summer [4]. It can also in some cases lead to lower thermal comfort in summer than in winter [5] or to summer overheating [6,7], but this cannot be generalized.

\footnotetext{
* Corresponding author at: Fraunhofer Institute for Solar Energy Systems ISE, Heidenhofstraße 2, 79110 Freiburg, Germany.

E-mail address: thibault.pflug@ise.fraunhofer.de (T. Pflug).
}

To reduce the risk of overheating and increased cooling loads, state-of-the-art solutions include for example the use of shading devices such as external blinds [8] or glazing solutions with reduced $g$-values [9]. Ventilation and free cooling are also traditional approaches to deal with cooling loads. In this case however, the increased airflow rate of external air led into the building brings the issues of filtering, pollution and allergies and can lead to substantial additional consumption of electricity to drive the ventilation fan. Opening windows can be effective but may create a security problem. One simple measure is to reduce the internal heat gains (equipment, etc.), but this is not always possible.

Another solution is switchable insulation. Switchable insulation is an insulating system which thermal resistance can be reduced:

- During the heating period, whenever the external environmental conditions (temperature, irradiance level) could be used to decrease the building's heating demand.

- During the cooling period, whenever the external temperature is low enough to decrease the building's cooling demand.

Existing switchable insulation concepts include for example the physical removal of the thermal insulation [10], the filling or emptying of a cavity with insulating foam spheres [11], the rear-ventilation of an insulation system [12], the collapse [13] or 


\begin{tabular}{|c|c|}
\hline \multicolumn{2}{|c|}{ Nomenclature } \\
\hline$g$ & $g$-value $[-]$ \\
\hline \multicolumn{2}{|c|}{$h_{\text {int }}$ and $h_{\text {ext }}$ internal and external heat transfer coefficients } \\
\hline I & $\begin{array}{l}\text { total (direct+diffuse) solar irradiance incident on the } \\
\text { facade }\left[\mathrm{W} \mathrm{m}^{-2}\right]\end{array}$ \\
\hline$J_{f t, i}, J_{b, i}$ & $\begin{array}{l}\text { total IR radiosity leaving the front and back surfaces } \\
\text { of the layer } i\left[\mathrm{~W} \mathrm{~m}^{-2}\right]\end{array}$ \\
\hline$q_{\text {solar }}$ & $\begin{array}{l}\text { heat gain due to solar irradiance, positive towards } \\
\left.\text { the interior [ } \mathrm{W} \mathrm{m}^{-2}\right]\end{array}$ \\
\hline$q_{\text {thermal }}$ & $\begin{array}{l}\text { heat loss due to temperature difference, positive } \\
\text { towards the exterior }\left[\mathrm{W} \mathrm{m}^{-2}\right]\end{array}$ \\
\hline$q_{\text {tot,in }}$ & $\begin{array}{l}\text { total heat flux through the back of the element, pos- } \\
\text { itive towards the interior [ } \mathrm{W} \mathrm{m}^{-2} \text { ] }\end{array}$ \\
\hline$S_{i}$ & solar irradiance absorbed in the layer $i\left[\mathrm{~W} \mathrm{~m}^{-2}\right]$ \\
\hline$T_{\text {ext }}, T_{\text {int }}$ & exterior and interior (room) air temperatures [K] \\
\hline$T_{f t, i}, T_{b, i}$ & $\begin{array}{l}\text { front and back surface temperatures of the layer } i \\
{[\mathrm{~K}]}\end{array}$ \\
\hline$t_{i}$ & thickness of the layer $i[\mathrm{~m}]$ \\
\hline$U, U_{f}, U_{w}$ & $\begin{array}{l}U \text {-value of the center-of-glazing, the frame, and } \\
\text { the whole window or facade element, respectively } \\
{\left[\mathrm{W} \mathrm{m}^{-2} \mathrm{~K}^{-1} \text { ] }\right.}\end{array}$ \\
\hline \multicolumn{2}{|c|}{ Greek letters } \\
\hline$\epsilon_{1}, \epsilon_{2}$ & $\begin{array}{l}\text { thermal emissivity of a layer facing the exterior and } \\
\text { the interior, respectively [-] }\end{array}$ \\
\hline$\theta_{\text {switch }}$ & $\begin{array}{l}\text { the switching temperature between heating and } \\
\text { cooling mode }\left[{ }^{\circ} \mathrm{C}\right]\end{array}$ \\
\hline$\theta_{\text {ext }}, \theta_{\text {int }}$ & $\begin{array}{l}\text { the external and internal (room) air temperature, } \\
\text { respectively }\left[{ }^{\circ} \mathrm{C}\right]\end{array}$ \\
\hline$\theta_{\text {ext }, 24}$ & $\begin{array}{l}\text { external air temperature averaged over the last } 24 \mathrm{~h} \\
{\left[{ }^{\circ} \mathrm{C}\right]}\end{array}$ \\
\hline$\lambda_{g v, i}$ & thermal conductivity of the layer $\left[\mathrm{W} \mathrm{m}^{-1} \mathrm{~K}^{-1}\right.$ ] \\
\hline$\rho_{\text {sol }}, \rho_{\text {vis }}$ & solar or visible reflectance $[-]$ \\
\hline$\tau_{\text {sol }}, \tau_{v i s}$ & solar or visible transmittance $[-]$ \\
\hline
\end{tabular}

removal $[14,15]$ of series of air cavities, the release and absorption of hydrogen gas by a metal hydride within a panel [16] and the change of internal pressure in nanomaterials [17]. Also, moving an insulation panel vertically within a double glazing to control convection in that facade element could be a promising way to switch the thermal resistance of the facade [18].

In this publication, the potential of a new switchable insulation concept is investigated. First, the new concept is presented. Then, the experimental setup is introduced, followed by the modelling approach and the boundary conditions of the case study presented in this contribution. The experimental results are then detailed, as well as the calculation results at the facade level. Finally the simulation results of the new switchable insulation in a building context and the impact of different parameters are presented.

\section{Operating principle of the removable insulation system}

The new, patented switchable insulation concept $[15,14]$ consists of a series of vertical parallel films that can be raised and wound around a drum or unwound and lowered. The drum is similar to the type used for conventional roller blinds. The series of vertical films is designed for integration in a closed cavity in order to minimize the effect of wind suction and pressure. The system can be mounted in front of an existing window like a traditional roller blind system, or in front of a massive opaque wall together with an additional external glass pane. Two operating states are possible for the films:
- In the insulating state, the opaque films are rolled down, creating $\mathrm{N}$ closed air cavities in series, which leads to a high thermal resistance and a low $U$-value. This is achieved by preventing convection in the air gaps due to the small air gap thickness. The opaque films combined with the high thermal resistance lead to a very low $g$-value which can be used to limit the cooling load during the cooling period.

- In the conducting state, the films are rolled up, achieving a low thermal resistance between the cover pane and the existing window or wall due to the large resulting air gap. Also, depending on the chosen front and back cover panes, a high solar transmittance can be achieved for the element.

Fig. 1 shows schematic drawings of the window element (window application) and the wall element in front of an opaque wall (wall application), in the insulating and conducting states. It should be noted that for the wall application, the element acts similarly to a Trombe wall in the conducting case, especially if the back cover is coated with a black, absorbing paint.

The films used in the prototypes were very thin polyethylene terephthalate (PET) layers, metallized on one side with an aluminum coating. The thickness of the film is $12 \mu \mathrm{m}$. Due to the very thin thickness of the films, their thermal resistance can be neglected compared to the thermal resistance of the air gaps. The measured thermal emissivity of the PET side was about 0.48 while the thermal emissivity of the metallized side was 0.03 [19].

\section{Experimental setup}

A first prototype of the removable insulation system was measured at Fraunhofer ISE, in the insulating state and in a vertical position. For this $U$-value measurement, a guarded hot plate apparatus supplied by Taurus was used in accordance with [20]. As a deviation from the standard, instead of using two samples for each measurement, the second sample was replaced by a reference sample, consisting of a $40 \mathrm{~mm}$ thick insulating Styrodur ${ }^{\circledR}$ (BASF) plate. This was taken into account for the uncertainty calculation according to the method of [20]. The total thermal resistance of the sample measured by the apparatus is converted to an $U$-value by adding the two standard boundary thermal resistances to the exterior and the interior environments, which are respectively $0.04 \mathrm{~m}^{2} \mathrm{KW}^{-1}$ and $0.13 \mathrm{~m}^{2} \mathrm{KW}^{-1}$ as defined for example in [21]. The measured values are centre of glazing values, the heat flux being measured over a $500 \mathrm{~mm} \times 500 \mathrm{~mm}$ central area, and the prototype area being $800 \mathrm{~mm} \times 800 \mathrm{~mm}$.

The measured prototype in the insulating state, as shown in Fig. 2, consisted of:

- A $2 \mathrm{~cm}$ thick wooden frame, with a depth of $95 \mathrm{~mm}$ and an area of $797 \mathrm{~mm} \times 797 \mathrm{~mm}$.

- 10 parallel vertical films, separated by air gaps of about $9 \mathrm{~mm}$ thickness, fixed on horizontal slats. In this version for testing purposes, the films and slats are not removable. The metallized PET films were all oriented in the same direction, with the metallized surfaces facing the cold plate of the $U$-value apparatus.

- Two 3 mm wide Plexiglas ${ }^{\circledR}$ layers, which act as the inner and outer cover. In total, there are consequently 11 air gaps.

\section{Modelling approach}

In this section, the modelling of the facade element, as well as the boundary conditions of the case study, is presented. 


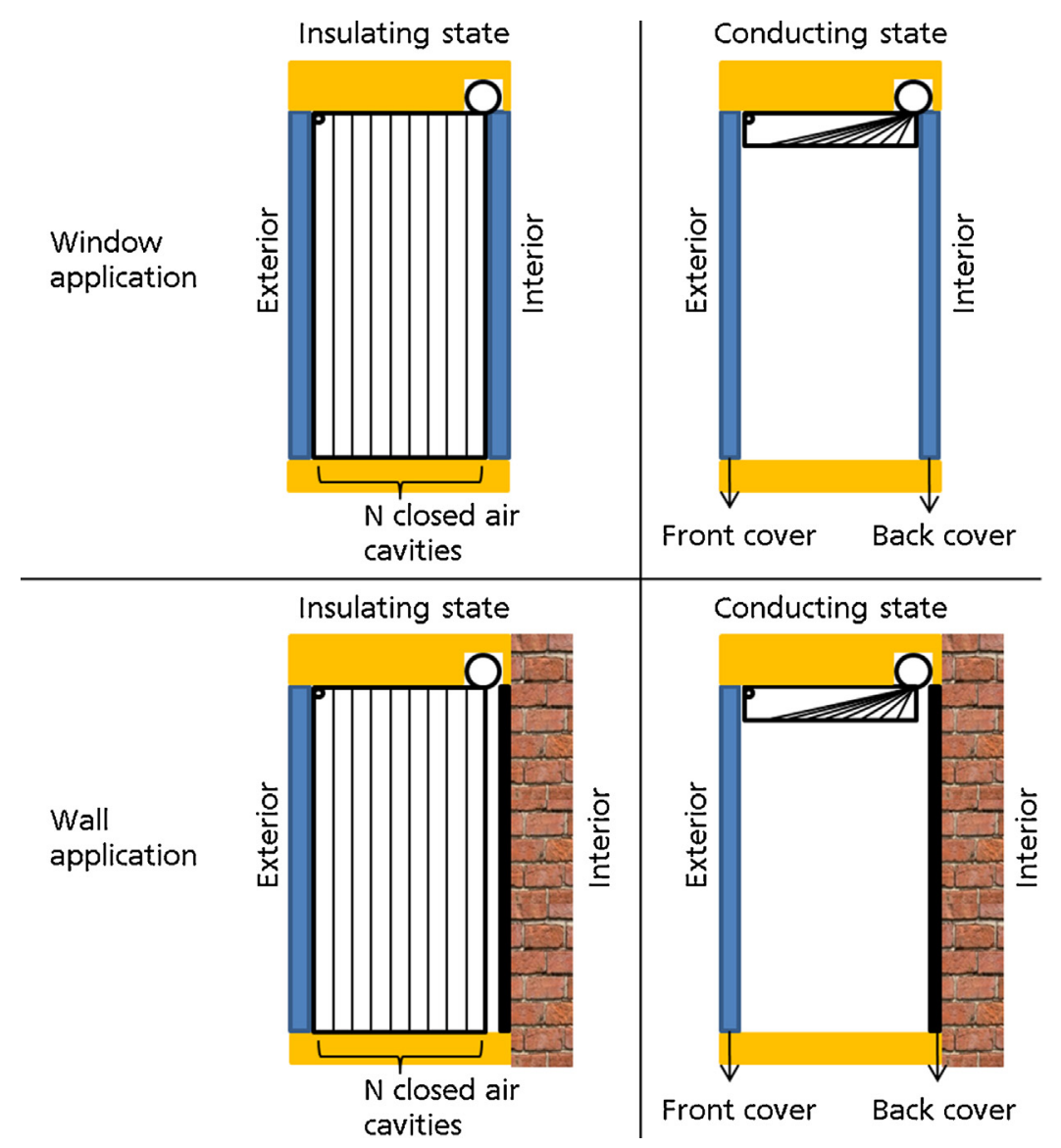

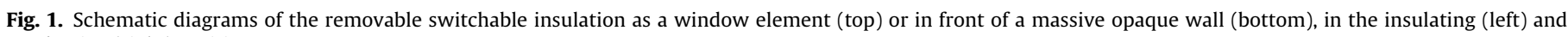
conducting (right) position.

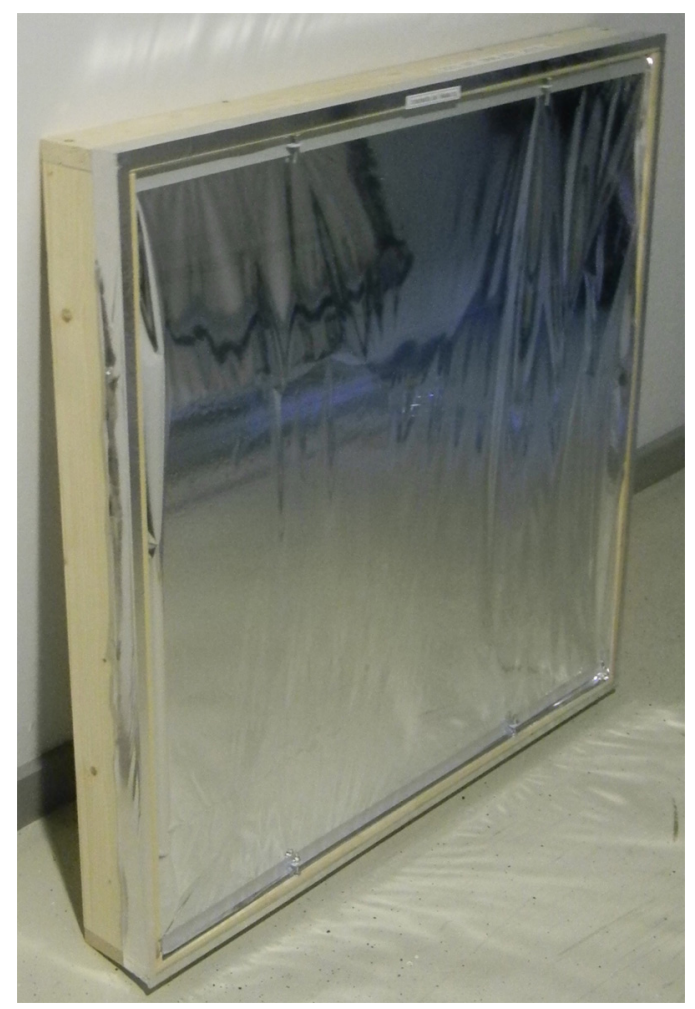

Fig. 2. External view of the tested sample.

\subsection{Facade and building model}

The new switchable facade element was analysed theoretically in two steps:

- First, the element was analyzed at the facade level without the building context to optimize the properties of the facade element with calculations based on the methods defined in the ISO 15099 standard [22].

- Then, promising variants of the facade elements were selected and integrated into reference rooms. The building energy demand for the rooms with the selected variants was simulated using the EnergyPlus simulation program [23].

For the thermal analysis of the whole element (from the outer pane to the inner pane through the stack of cavities) without the building context, the nodal model presented in ISO 15099 [22] is used. This model was designed for the calculation of the layer-tolayer heat transfer through fenestration systems. One of the main advantages of this model is that it can easily be extended to a varying number $N$ of cavities, and implemented with a programming code. The main assumptions are uniform surface temperatures for each layer over the height and width, steady state calculation, (justified in this case by the very low thermal inertia of the films) and convective heat transfer coefficients which are assumed to be constant and equal to the average value over the height of the glazed and insulation areas. The radiosity method, where the IR heat fluxes are explicitly calculated under the assumption of grey diffuse surfaces [24], is used for the IR heat transfer between the layers. The advantage of this method is that it can be used to model infrared- 
transparent layers. The ISO 15099 model was implemented in the programming language Python 3.4 [25]. For each thermal node, the energy balance results in the following set of equations:

$q_{i}=h_{c v, i}\left(T_{f t, i}-T_{b, i-1}\right)+J_{f t, i}-J_{b, i-1}$

$q_{i}=S_{i}+q_{i+1}$

$J_{f t, i}=\epsilon_{f t, i} \sigma T_{f t, i}^{4}+\tau_{i} J_{f t, i+1}+\rho_{f t, i} J_{b, i-1}$

$J_{b, i}=\epsilon_{b, i} \sigma T_{b, i}^{4}+\tau_{i} J_{b, i-1}+\rho_{b, i} J_{f t, i+1}$

$T_{b, i}-T_{f t, i}=\frac{t_{i}\left(2 q_{i+1}+S_{i}\right)}{2 \lambda_{g v, i}}$

With:

- $T_{f t, i}[\mathrm{~K}]$ the front surface temperature of the node or layer $i$.

- $T_{b, i-1}[\mathrm{~K}]$ the back surface temperature of the node or layer $i-1$.

- $J_{f t, i}\left[\mathrm{~W} \mathrm{~m}^{-2}\right]$ the total IR radiosity leaving the front surface of the node or layer $i$.

- $J_{b, i-1}\left[\mathrm{~W} \mathrm{~m}^{-2}\right]$ the total IR radiosity leaving the back surface of the node or layer $i-1$.

- $q_{i}\left[\mathrm{~W} \mathrm{~m}^{-2}\right]$ the total heat flux leaving the layer $i$ towards the layer $i-1$.

- $S_{i}\left[\mathrm{~W} \mathrm{~m}^{-2}\right]$ the solar irradiance absorbed in the layer $i$.

- $h_{c v, i}\left[\mathrm{~W} \mathrm{~m}^{-2} \mathrm{~K}^{-1}\right]$ the convective heat transfer coefficient between layer $i$ and $i-1$.

- $t_{i}[\mathrm{~m}]$ the thickness of the layer.

- $\lambda_{g v, i}\left[\mathrm{~W} \mathrm{~m}^{-1} \mathrm{~K}^{-1}\right]$ the thermal conductivity of the layer $i$.

- $\epsilon, \tau, \rho[-]$ the infrared properties of the layer.

For the building simulation, the EnergyPlus simulation program [23] was used. This program also uses the ISO 15099 [22] standard for the thermal modelling of facade elements. To model the window application, the element in the conducting state was represented by a conventional double glazed window. The switching to the insulating state was then handled using the Energy Management System (EMS) capability of EnergyPlus. Among other purposes, the EMS can be used to switch facade element dynamically based on inputs or building variables. In the insulating state, with the films rolled down, the element has been implemented with (from the exterior towards the interior) an equivalent layer, one film and the inner pane, allowing the inner surface temperature of the element to be calculated accurately. The equivalent layer was an opaque layer with an equivalent thermal resistance, so that the total thermal resistance of the system was represented accurately.

To model the wall component, the Trombe wall approach was used. This approach has been developed and validated in [26]. The Trombe wall cavity is represented by a thermal zone in which the internal convection is handled by the correlations introduced by [27]. In our case, this approach is valid for the conducting state, when the films are rolled up and there is only one cover pane within a certain distance of the massive wall. In the insulating case, this approach was adapted accordingly by virtually deactivating the thermal resistance of the air layer within the Trombe wall and giving an equivalent thermal resistance to the outer pane. Finally, the facade element is switched using the EMS approach.

\subsection{Reference office room and climate}

For the case study, a room of a well-insulated office building was simulated. An office building was chosen because, in this case, internal gains often cause cooling loads even if outdoor temperatures are lower than indoor temperatures. This is then a promising application case for the switchable insulation system. To simplify the problem, a shoebox geometry is simulated. The simulated room has one exterior south facade and five adiabatic internal surfaces

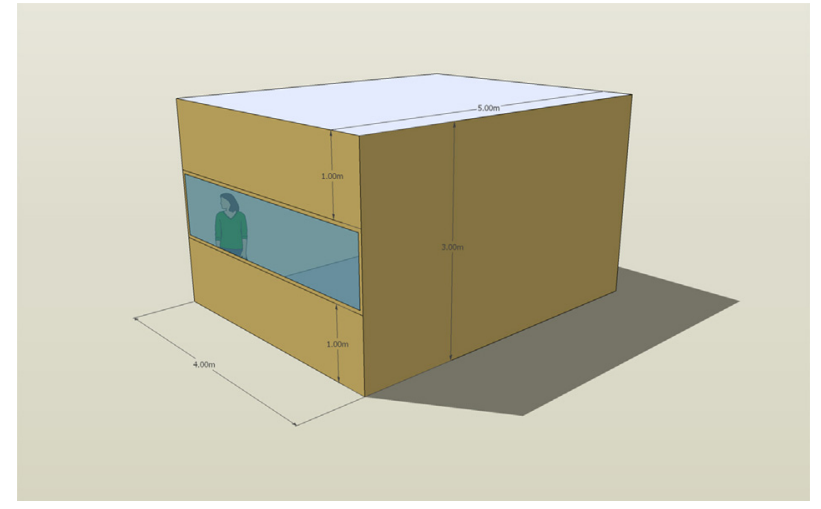

Fig. 3. Geometry of the simulated room.

Table 1

Details of the simulated reference office room

\begin{tabular}{lll}
\hline Name & Value & Unit \\
\hline Glazed area (south window) & 3.5 & $\mathrm{~m}^{2}$ \\
Frame area (south window) & 0.5 & $\mathrm{~m}^{2}$ \\
$U_{w}$-value (south window) & 0.76 & $\mathrm{~W} \mathrm{~m}^{-2} \mathrm{~K}^{-1}$ \\
g-Value (south window) & 0.60 & - \\
$U$-value of the south wall & 0.15 & $\mathrm{~W} \mathrm{~m}^{-2} \mathrm{~K}^{-1}$ \\
Internal gains due to lighting & 10 & $\mathrm{~W} \mathrm{~m}^{-2}$ \\
Total heat gain per person & $150[28]$ & $\mathrm{W}$ \\
Occupancy (07:00-18:00, weekdays) & 2 & $\mathrm{People}$ \\
Equipment (07:00-18:00, weekdays) & 15 & $\mathrm{~W} \mathrm{~m}{ }^{-2}$ \\
Heating setpoint (05:00-18:00, weekdays) & 24 & ${ }^{\circ} \mathrm{C}$ \\
Heating setpoint (else) & 17 & ${ }^{\circ} \mathrm{C}$ \\
Cooling setpoint (05:00-18:00, weekdays) & 24 & ${ }^{\circ} \mathrm{C}$ \\
Cooling setpoint (else) & 28 & ${ }^{\circ} \mathrm{C}$ \\
External airflow rate per person & 40 & $\mathrm{~m}^{3} \mathrm{~h}^{-1}$ \\
Heat recovery rate (sensible) & 75 & $\%$ \\
\hline
\end{tabular}

(three vertical internal walls, one roof and one ceiling). All walls are composed of $15 \mathrm{~cm}$ of concrete. The southern external wall is also insulated with $20 \mathrm{~cm}$ of polyurethane on the external side. The middle third of the south facade was occupied by the triple glazed window. The geometry and details of the simulated room are shown in Fig. 3 and Table 1, respectively.

To avoid glare and reduce the cooling load, the window is equipped with an external Venetian blind with horizontal slats which is activated when the irradiance on the external surface exceeds $150 \mathrm{~W} \mathrm{~m}^{-2}$. The slat angle between the normal to the horizontal blind slat and the normal to the glazing is then $25^{\circ}$. In the room, the artificial lighting is turned on and modulated if the illuminance in the room drops below 500 lux [29].

European climatic conditions have been analyzed in depth within the European INSPIRE project [30], resulting in differentiation between seven different climates in Europe considering air temperature ranges, heating and cooling degree-days as well as humidity. Among these, the continental climate was selected as the most appropriate for switchable insulation technologies because of the following criteria:

- Heating-dominated climate, to justify the need for insulation in winter, but still a significant share of cooling demand in the case of high solar gains and/or high internal gains.

- Significant irradiance levels, to be able to use the solar radiation in winter for passive solar heating and because of the need to manage cooling loads in summer.

- Appreciable temperature variation between day and night, to benefit from the ability to switch the thermal resistance of the facade on and off. 
The continental climate is represented by the city of Stuttgart and can be considered to be representative for Central Europe (Germany, Austria, Czech Republic, Slovakia, Hungary, etc.) as well as parts of Ukraine, Poland and Romania. This climate shows an amplitude of $43 \mathrm{~K}$ between the extreme summer and winter temperatures and during more than $10 \%$ of the year, the ambient air temperature is negative [30]. Also, even in summer, the minimum air temperature during the night remains below $10^{\circ} \mathrm{C}$, which should allow the use of the switchable insulation to cool down the building.

\subsection{Variants}

To assess the potential of the new switchable insulation concept, different variants were tested for the southern external facade, as shown in Fig. 4.

The reference facade is divided into three horizontal bands: one window band in the middle (1-2 m height), and two insulated opaque areas (lower and upper parts). Two variants are defined:

- For the window application, the entire upper part of the facade (insulation and concrete wall) is replaced by the switchable element, with solar glass as the front and back covers. Solar glass is low-iron glass with high solar transmittance. Only the upper part of the reference facade is replaced, because from the daylighting perspective the benefit of having a transparent element in the lower third $(1 \mathrm{~m})$ of the facade is low. Also, to replace the existing window with the window element is not possible since when the element is in the insulating state, it is completely opaque and no view contact to the outside would then be possible.

- For the wall application, the external insulation in front of the opaque surface is replaced by the switchable element.

The ratio between window area and frame area was assumed to be the same as for the reference window. Also, the $U$-value of the frame was assumed to be the same $\left(0.85 \mathrm{~W} \mathrm{~m}^{-2} \mathrm{~K}^{-1}\right)$, since no final details of the frame and of the magnitude of possible boundary effects at the edges of the films were available.

The electrical consumption of the motor needed to roll the films up or down has been neglected due to the low electrical power from roller shutter motors and the low activation time.

\subsection{Control strategies}

The control strategies focused on energy-saving considerations, neglecting visual comfort. Two control strategies have been developed, for which two operating modes can be activated during the year: a heating-dominated mode and a cooling-dominated mode. The switching between these two modes is based on the mean outdoor air temperature over the previous $24 \mathrm{~h}$. Compared to a strategy based on fixed heating and cooling periods for a location, this strategy performs better during mid-season because of periods with alternating heating and cooling demands. In the case of the window application, only the upper third of the facade is replaced, and since it was assumed that the users are located relatively close to the facade, glare is not taken into consideration.

The two control strategies proposed are the following:

- A simple control strategy that is easy to implement in a programming code: in the heating mode, the element is switched from the insulating to the conducting state when the outdoor air temperature is higher than the interior one or when the total solar irradiance incident on the southern facade is greater than $150 \mathrm{~W} \mathrm{~m}^{-2}$, or when both conditions are met. Otherwise, it is in the insulating state. In the cooling mode, the element is switched to the conducting state only when the outdoor air temperature is below the indoor one and the irradiance is below $150 \mathrm{~W} \mathrm{~m}^{-2}$. The influence of the $150 \mathrm{~W} \mathrm{~m}^{-2}$ limit has been investigated. For the wall application, the outdoor air temperature is not compared to the room air temperature but to the external surface temperature of the massive wall (behind the switchable element's back cover). The reason is that, due to the thermal mass, this surface temperature is more significant than the indoor temperature as the limit to determine whether the element is switched to the conducting or insulating state. The advantage of this control strategy is that the four inputs are easy to measure and need only to be compared logically to each other or to a fixed limit. In a real case it is assumed that the four inputs would be determined in one or a few representative rooms of a building.

- An advanced control strategy. Here, the predicted heat transfer for the current time step is calculated, assuming that the element is in the conducting state and that the thermal and radiative conditions remain constant for the whole time step. If in heating mode, the element is switched to the conducting state if the predicted total heat flux through the back of the element is positive (energy flowing towards the room). For the cooling mode, the opposite strategy is applied. The total heat flux through the back of the switchable element $\left(\mathrm{W} \mathrm{m}^{-2}\right)$ is predicted in a simplified way with the following formulas:

$q_{\text {tot }, \text { in }}=q_{\text {solar }}-q_{\text {thermal }}$

With $\mathrm{q}_{\text {thermal }}\left(\mathrm{W} \mathrm{m}^{-2}\right)$ the heat loss due to a temperature difference, defined as:

$q_{\text {thermal }}=U\left(T_{\text {int }}-T_{\text {ext }}\right)$

And $\mathrm{q}_{\text {solar }}\left(\mathrm{W} \mathrm{m}^{-2}\right)$ the heat gain due to solar irradiance, defined as:

$q_{\text {solar }}=g I$

With:

- $U\left[\mathrm{~W} \mathrm{~m}^{-2} \mathrm{~K}^{-1}\right]$ the $U$-value of the element (calculated without solar irradiance).

- $T_{\text {int }}[\mathrm{K}]$ the interior (room) air temperature at the beginning of the timestep.

- $T_{\text {ext }}[\mathrm{K}]$ the exterior air temperature at the beginning of the timestep.

- $g[-]$ the $g$-value of the element.

- $I\left[\mathrm{~W} \mathrm{~m}^{-2}\right]$ the total (direct + diffuse) incident solar irradiance on the element at the beginning of the timestep.

For the wall element, the room air temperature was also replaced by the external surface temperature of the massive wall. Modified definitions of the U- and $g$-value have been used, which includes only the heat transport between the exterior environment and the massive wall (instead of the interior) so that the heat flux predicted for the advanced control strategy is the heat flux from the facade element to the massive wall. This results in higher $U$ - and $g$-values than in Table 4. For the $g$-value, the calculated hemispherical value for diffuse irradiance is used. The consequence is that for direct irradiance and small incidence angles (winter situations), the $g$-value is slightly underestimated, while for high incidence angles the $g$-value is overestimated. The $g$-value is modelled correctly for diffuse incident solar irradiance.

The two control strategies are visually summarized in Figs. 5 and 6.

\section{Results and discussion}

In this section, the results of the experimental and theoretical investigation at the facade level are presented. Then, the building simulation results for the window and wall application are 


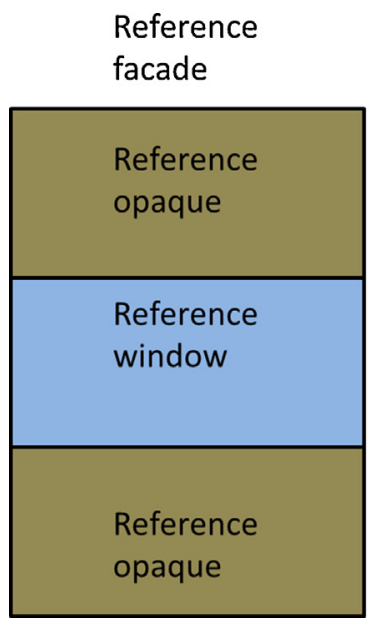

Variant: wall

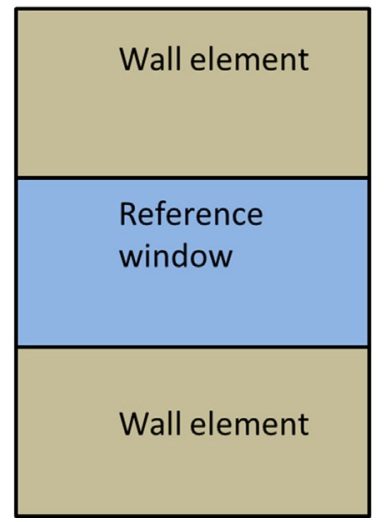

Variant: window

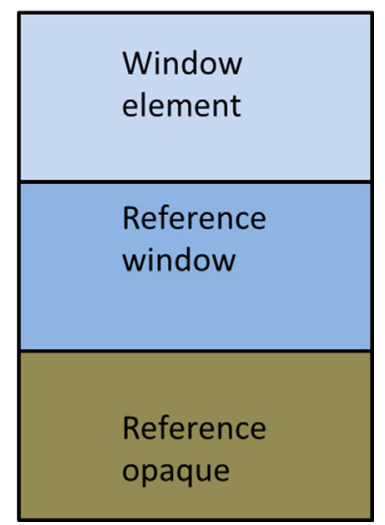

Fig. 4. Reference facade and variants with switchable insulation.

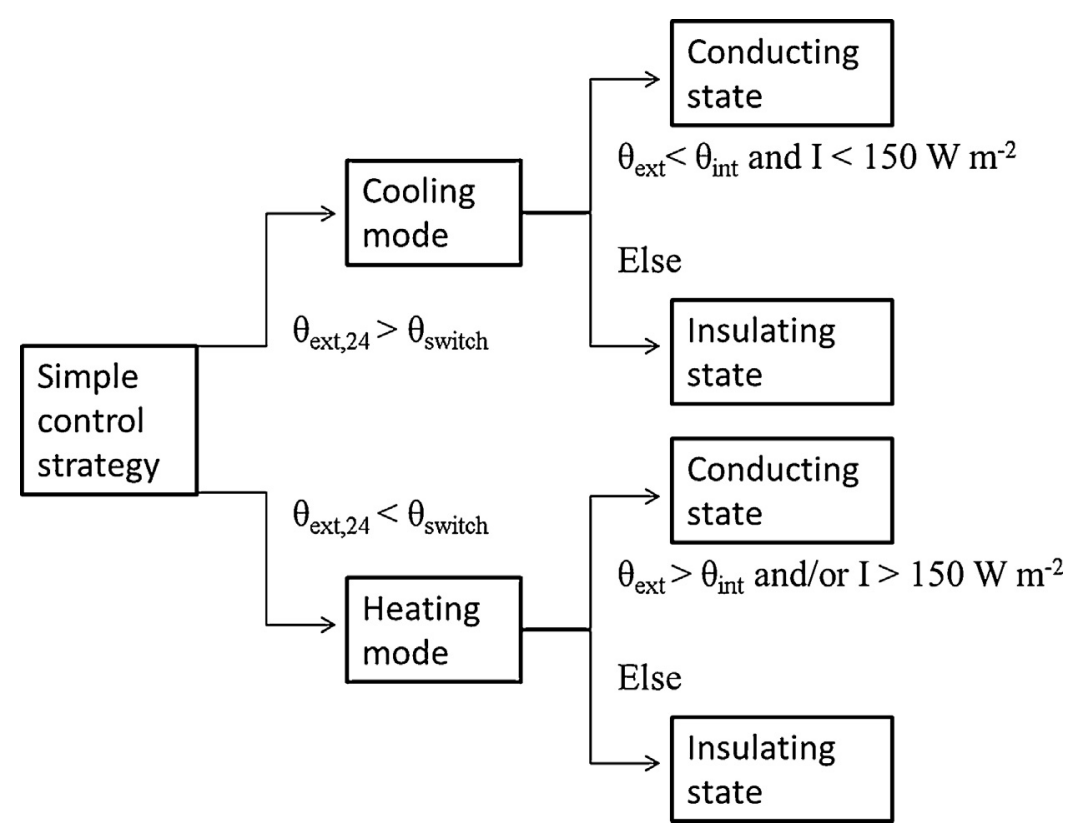

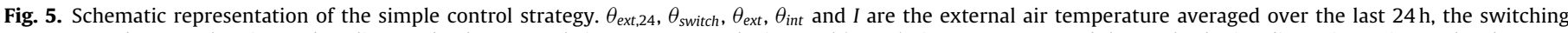

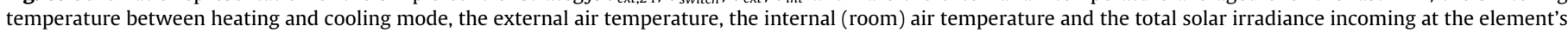
outer surface, respectively.

discussed, before investigating the influence of thermal mass and orientation.

\subsection{Experimental results and comparison with ISO 15099}

The experimental results are shown in Table 2 and compared to the ISO 15099 calculation in Fig. 7.

The measured thermal resistance and thus the resulting $U$-value vary with both the average temperature and the temperature difference, as shown in Table 2. However, with air gap thicknesses of less than $1 \mathrm{~cm}$ and an aspect ratio larger than 80 for each cavity, such variations are not expected. The reason is that the air in each cavity should be in the gas conduction range, with no convection (Nusselt $\approx 1)$. As the thermal conductivity of the air layer is only slightly temperature-dependent and since the IR radiative heat exchange is minimized by the low-e layers, no large temperature dependence is expected. The theoretical values are considered to be accurate, because of the fact that the air layers in the gaps are in conduction mode and since there is no difference between
Table 2

$U$-value measurement results. $\theta_{\text {cold }}$ and $\theta_{\text {warm }}$ are the temperatures of the cold and warm boundary surfaces, respectively. $\theta_{\text {mean }}$ and $\delta T$ are the mean and the difference between these temperatures, respectively. The label corresponds to $\delta T-\theta_{\text {mean }}$ couples.

\begin{tabular}{llllll}
\hline $\begin{array}{l}\text { Label } \\
\text { Unit }\end{array}$ & $\begin{array}{l}\theta_{\text {cold }} \\
{ }^{\circ} \mathrm{C}\end{array}$ & $\begin{array}{l}\theta_{\text {warm }} \\
{ }^{\circ} \mathrm{C}\end{array}$ & $\begin{array}{l}\delta T \\
\mathrm{~K}\end{array}$ & $\begin{array}{l}\theta_{\text {mean }} \\
{ }^{\circ} \mathrm{C}\end{array}$ & $\begin{array}{l}U \text {-value } \\
\mathrm{W} \mathrm{m}^{-2} \mathrm{~K}^{-1}\end{array}$ \\
\hline $10-10$ & 5.0 & 14.9 & 9.9 & 10.0 & $0.35 \pm 0.03$ \\
$10-20$ & 14.7 & 24.6 & 9.8 & 19.7 & $0.40 \pm 0.03$ \\
$10-30$ & 24.4 & 34.2 & 9.8 & 29.3 & $0.44 \pm 0.04$ \\
$5-20$ & 16.9 & 21.8 & 4.9 & 19.4 & $0.35 \pm 0.03$ \\
$20-20$ & 10.3 & 30.0 & 19.8 & 20.1 & $0.45 \pm 0.04$ \\
\hline
\end{tabular}

different empirical heat transfer correlations for this case due to the small gap thickness and the large aspect ratio. This is further detailed in [19].

When comparing the measured values to the ISO 15099 standard, the measured $U$-values are always higher than the calculated ones and have a stronger temperature dependence. For this pro- 


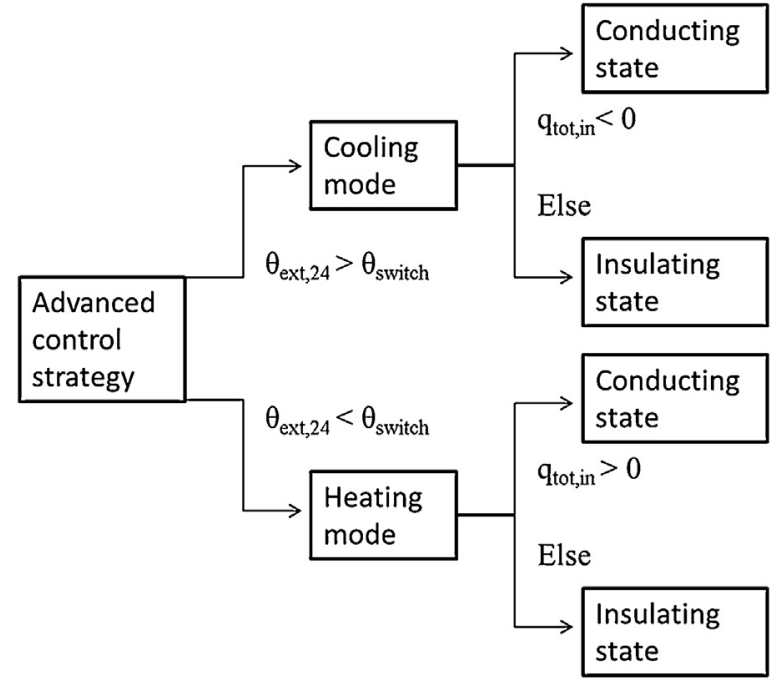

Fig. 6. Schematic representation of the advanced control strategy. $\theta_{\text {ext,24 }}, \theta_{\text {switch }}$ and $q_{\text {tot,in }}$ are the external air temperature averaged over the last $24 \mathrm{~h}$, the switching temperature between heating and cooling mode and the total predicted heat flux through the back of the switchable element, respectively.

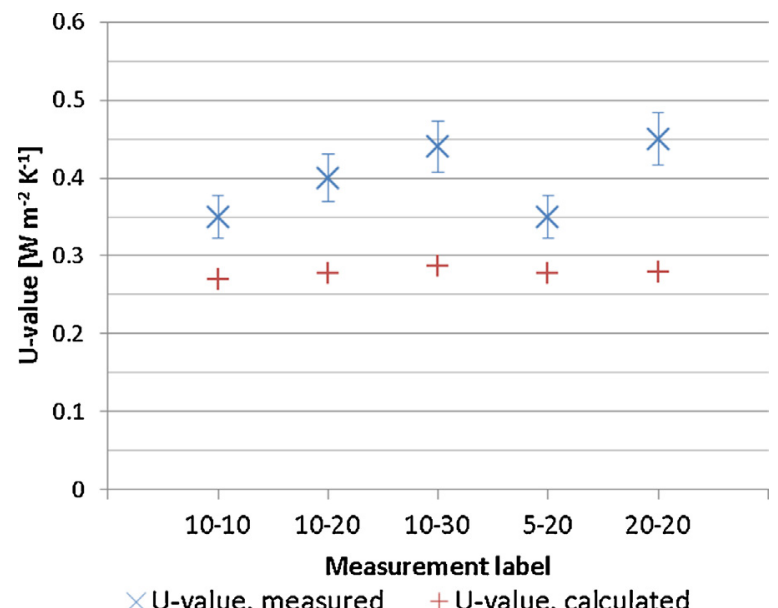

Fig. 7. Calculated versus measured $U$-values. The label corresponds to $\delta T-\theta_{\text {mean }}$ couples, with $\theta_{\text {mean }}\left[{ }^{\circ} \mathrm{C}\right]$ and $\delta T[\mathrm{~K}]$ the mean and the difference between these temperatures, respectively.

totype, the films were not fixed to the wooden frame, and the connection to the frame was loose. Consequently the airtightness assumed for the ISO 15099 calculation was not achieved. Thus, heat and mass transfer is possible to some extent between two adjacent air cavities, leading to a higher $U$-value. From the mechanical point of view, the design can be optimized by increasing the airtightness at the sides, top and bottom while still allowing the films to be rolled up and down, in order to converge to the optimum shown by the model. For the building simulation, the optimal element as calculated by the standard will be simulated, before taking into account the higher $U$-value of the existing prototype in the insulating state and assessing its impact on the overall performance of the element.

\subsection{Preliminary analysis at the facade level}

In a preliminary step, steady-state calculations were performed using the ISO 15099 standard. The whole system is delimited by a glass pane or a wall on the interior side, and an external cover glazing. Between the two cover layers, the multilayer insulation is rolled down (insulating state) or up (conducting state). It has been shown in [19] that an optimum thickness of the gap between two adjacent films is $1 \mathrm{~cm}$. This optimum has been chosen in order to make sure that the heat transfer between two films is in the conduction regime (Nusselt $=1$ ) which ensures the most efficient insulation function, while having a limited number of films. The infrared properties of the films were measured [19], resulting in a thermal emissivity of $\epsilon=0.031$ for the metallized side of each film, and $\epsilon^{\prime}=0.479$ for the PET side. The different variants investigated are listed in Table 3.

The external and internal covers were assumed to be opaque for IR radiation. It was also assumed that the covers are clear and nonscattering, so that the transmittance is equal for light coming from the external side and the reflected light coming from the internal side of the cover [19]. The solar, visible and IR properties were taken from the WINDOW7.2 database [31].

Also, the effect of the number of cavities in the insulating state and the thickness of the resulting air gap between the cover layers in the conducting state has been investigated. For the calculations of the $U$-value in the insulating state, a temperature difference of $25 \mathrm{~K}$ was assumed between the interior (room) and the exterior environments to get conservative results. Standard internal and external boundary heat transfer coefficients of $h_{\text {int }}=7.7 \mathrm{~W} \mathrm{~m}^{-2} \mathrm{~K}^{-1}$ and $h_{\text {ext }}=25 \mathrm{~W} \mathrm{~m}^{-2} \mathrm{~K}^{-1}$ were chosen [32] to be able to compare the results with state-of-the-art facade systems. In the conducting state, two temperature differences were chosen to assess the temperature dependence.

For the calculation of the $g$-value in the conductive case, winter boundary conditions were chosen, with the mean of the room air and outdoor air temperatures being $10^{\circ} \mathrm{C}$, and a direct solar irradiance of $500 \mathrm{~W} \mathrm{~m}^{-2}$ incident at the facade with $0^{\circ}$ incidence angle. The amount of solar energy absorbed in each layer was calculated using WINDOW 7.2 (Lawrence Berkeley National Laboratory 2015). It has been shown in [19] that the $g$-value in the insulating case is negligible due to the high thermal resistance between the exterior absorbing surfaces and the room and the fact that the films are opaque.

The influence of the number of cavities in the insulating case and the total thickness of the resulting cavity in the conducting case is shown as an example for the window application in Fig. 8, with following variants:

- SS: solar glass as the outer and inner covers.

- SK: solar glass as the outer cover and K-glass as the inner cover.

- KS: K-glass as the outer cover and solar glass as the inner cover.

In the insulating case, with a number of cavities between 2 and 5 , the SK variant has the lowest $U$-value. This is due to the fact that in the innermost cavity, the K-glass, facing a PET surface, diminishes the IR exchange. For the KS surface, in the outermost cavity the Kglass does not bring much benefit since it is facing the low-e surface of the exterior film, while on the surfaces in the innermost cavity there is no low-e layer. For larger numbers of cavities, the difference in the $U$-values between the three variants becomes smaller and smaller.

In the conductive case (with a large air gap between the covers due to the retracted films), the transition to the convection regime is achieved in the first centimetres. For more relevant distances between the two cover panes, an almost constant $U$-value is reached, which depends on the temperature: the additional insulating air thickness compensates the increasing closed-cavity convection. The solar glass-solar glass solution (SS) offers the highest $U$-value in the conducting state of about $2.75 \mathrm{~W} \mathrm{~m}^{-2} \mathrm{~K}^{-1}$. In the conducting state, the cases SK and KS are identical with lower values due to lower infrared radiative exchange. Also, the dependence on the temperature difference increases due to the greater impor- 
Table 3

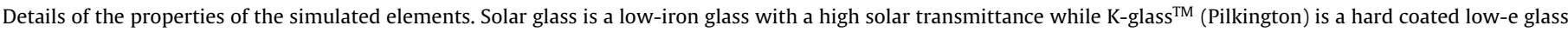

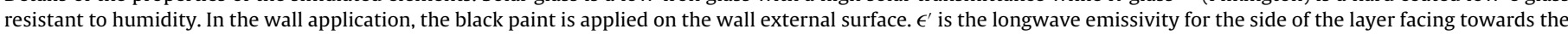
room.

\begin{tabular}{|c|c|c|c|}
\hline Name & Outer cover & Inner cover & Application \\
\hline SS & $\begin{array}{l}\text { Solar glass: } \tau_{\text {sol }}=0.910, \rho_{\text {sol }}=0.079 \text {, } \\
\tau_{\text {vis }}=0.916, \epsilon=0.84, \epsilon^{\prime}=0.84\end{array}$ & Solar glass & Window \\
\hline SK & Solar glass & $\begin{array}{l}\text { K-glass: } \tau_{\text {sol }}=0.704, \rho_{\text {sol }}, 1=0.106 \\
\rho_{\text {sol }, 2}=0.118, \tau_{\text {vis }}=0.825, \epsilon=0.173 \\
\epsilon^{\prime}=0.837\end{array}$ & Window \\
\hline KS & $\begin{array}{l}\text { K-glass: } \tau_{\text {sol }}=0.704, \rho_{\text {sol }}, 1=0.106 \\
\rho_{\text {sol, }, 2}=0.118, \tau_{v i s}=0.825, \epsilon=0.837 \\
\epsilon^{\prime}=0.173\end{array}$ & Solar glass & Window \\
\hline SB & Solar glass & $\begin{array}{l}\text { Black paint: } \tau_{\text {sol }}=0, \rho_{\text {sol }}=0.055, \tau_{v i s}=0 \text {, } \\
\epsilon=0.90\end{array}$ & Wall \\
\hline SB + low-e & Solar glass & $\begin{array}{l}\text { Black paint + low-e: } \tau_{\text {sol }}=0, \rho_{\text {sol }}=0.055 \text {, } \\
\tau_{v i s}=0, \epsilon=0.03\end{array}$ & Wall \\
\hline
\end{tabular}

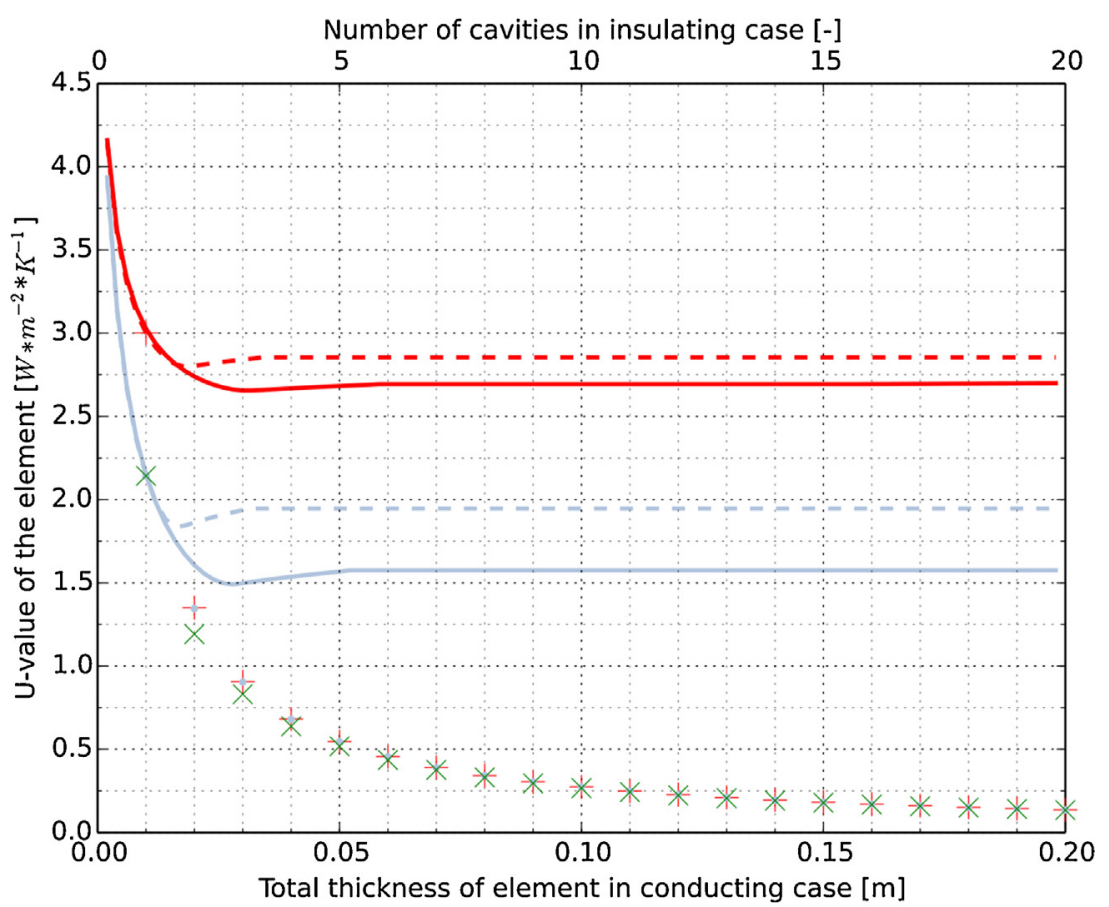

\begin{tabular}{|c|c|}
\hline & SS, conducting state $\mathrm{dT}=5 \mathrm{~K}$ \\
\hline- & SS, conducting state, $d T=25 \mathrm{~K}$ \\
\hline & $\mathrm{KS}=\mathrm{SK}$, conducting state, $\mathrm{dT}=5 \mathrm{~K}$ \\
\hline & $\mathrm{KS}=\mathrm{SK}$, conducting state, $\mathrm{dT}=25 \mathrm{~K}$ \\
\hline+ & SS, insulating state \\
\hline - & $\mathrm{KS}$, insulating state \\
\hline$x$ & SK, insulating state \\
\hline
\end{tabular}

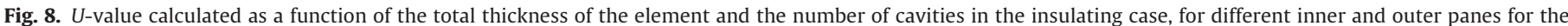
window application. The thickness of the cavities in the insulating case is fixed $(1 \mathrm{~cm})$. The element average temperature is $21^{\circ} \mathrm{C}$.

tance of the convective resistance relative to the infrared thermal resistance.

Based on these $U$-value results, it seems reasonable to have a large number of cavities or overall thickness, since after the first $5 \mathrm{~cm}$ the $U$-value in the conducting state does not diminish anymore, while the $U$-value in the insulating case continues to decrease, thus increasing the difference between the $U$-value in the conducting and insulating states. For the wall element, a low-e layer on the wall has a small, almost negligible effect in the insulating state but significantly decreases the $U$-value in the conducting state.

In Fig. 9, the g-value dependence on the thickness of the air gap between the inner and outer covers is shown in the conducting case for the wall element. In this case, the following variants are studied:
- SB: solar glass as the outer cover and black paint on the wall as the inner cover.

- SB + low-e: solar glass as the outer cover and black paint plus a low-e layer on the wall as the inner cover.

A high $g$-value in the conducting state allows solar energy to be collected during sunny days in the heating period. The greater the thermal resistance is between the outer and inner covers, the less absorbed solar energy flows towards the exterior, since most of the solar energy is absorbed by the black paint. For the same reason, the variant with low-e properties shows a higher $g$-value. The maximum of the $g$-value corresponds to the maximum of the convective thermal resistance: for a thickness below $1 \mathrm{~cm}$, the air gap is in the gas conduction range and the thermal resistance increases linearly 


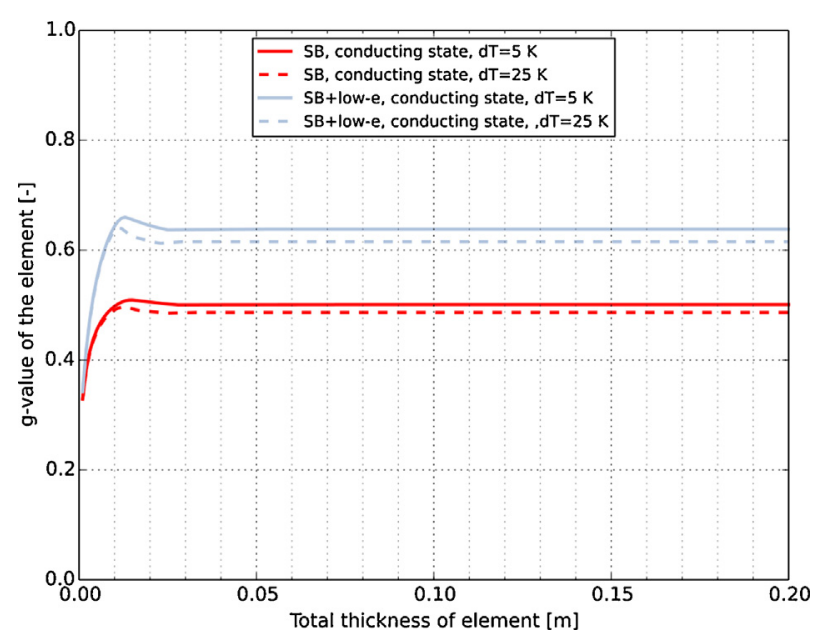

Fig. 9. $g$-Value calculated as a function of the total thickness of the element, for different inner and outer panes for the application on the wall.

with the thickness. The thermal resistance reaches a minimum around $1.2 \mathrm{~cm}$, after what convection starts. Finally, the increasing air thickness compensates the convection for greater thicknesses. For the case with low-e properties, the difference between the two temperature differences is more important than in the case with standard black paint. This is due to the fact that in the selective paint case, the convective heat transport is more important. For the case without selective paint, where the influence of IR radiation in the cavity is slightly higher due to the absence of low-e layer, it has been checked that the influence of the average temperature is very low.

Finally, two variants were selected for the investigation at building level presented in this publication, based on:

- The maximum switching range between low and high $U$-values.

- The maximum switching range between low and high g-values. Note that the $g$-value in the insulating case is negligible due to the high thermal resistance [19].

A thickness of $20 \mathrm{~cm}$ between the inner and outer covers was chosen, corresponding to twenty air cavities. For this thickness, the ratio between the $U$-value in the insulating and conducting states is competitive (factor of about 19) while the total thickness is comparable to the insulation thickness of a passive house. For the wall application, the variant without a low-e coating was selected, as greater priority was given to the summer night cooling than to the heating during the heating period. The properties of the facade configurations selected for the wall and window application are summarized in Table 4.

\subsection{Window application}

In Fig. 10, the building simulation results for the window variant are shown:

- The first column from the left shows the results for the reference facade.

- The second column shows results for the upper portion of the exterior south wall being replaced by the switchable facade element, but always in the insulating state (films always down).

- Then, a second simulation is done with the element always in the conducting state to obtain the results in the third column.

- Then, the element is operated with the simple control strategy as defined previously, with the results being shown in the fourth column.

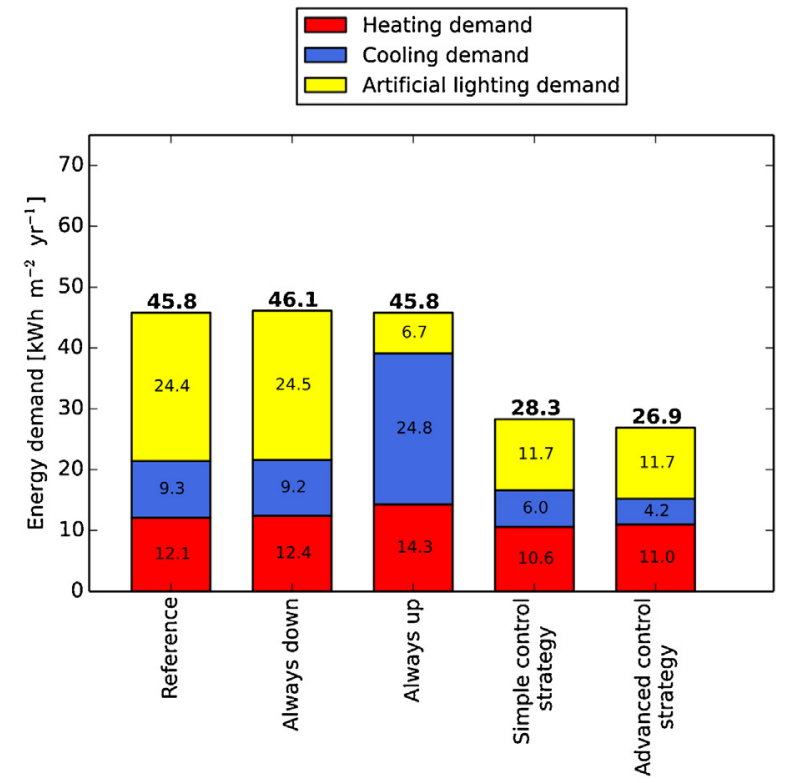

Fig. 10. Building simulation results: window application. Results expressed in useful energy.

- Finally, the element is operated with the advanced control strategy as defined previously, and the results are presented in the fifth column.

The reference room has an energy demand similar to a passive house [33], with heating and cooling demands below $15 \mathrm{kWh} \mathrm{m}^{-2}$. The artificial lighting demand is high, due to the illuminance setpoint of 500 lux in the room as well as the power of the artificial lighting system of $10 \mathrm{~W} \mathrm{~m}^{-2}$.

The difference between the case "Always down" and the reference is explained by the much lower thermal mass in the upper part of the facade and the influence of the lower $U$-value of the frame, which is 0.85 instead of $0.15 \mathrm{~W} \mathrm{~m}^{-2} \mathrm{~K}^{-1}$ for the reference opaque wall.

When the switchable element is always in the conducting state, the reduction of the artificial lighting demand is compensated by the additional cooling demand due to solar gains and by the additional heating demand due to higher thermal losses in winter, which are not compensated by the additional solar gains.

With the simple control strategy and compared to the reference, there is a reduction by $22 \%\left(4.8 \mathrm{kWh} \mathrm{m}^{-2}\right)$ in the sum of heating and cooling demands: the cooling demand is reduced by $3.3 \mathrm{kWh} \mathrm{m}^{-2}$ (36\%) and the heating demand by $1.5 \mathrm{kWh} \mathrm{m}^{-2}(12 \%)$. Due to the replacement of an opaque area with the switchable element with a high transmittance in the conducting state, the artificial lighting is reduced by $12.7 \mathrm{kWh} \mathrm{m}^{-2}$ (52\%). For this simple control strategy, the system was in the insulating state $47 \%$ of the time during the year.

With the advanced control strategy and compared to the reference, the reduction of the sum of the heating and cooling demands reaches $29 \%\left(6.2 \mathrm{kWh} \mathrm{m}^{-2}\right)$ : the cooling demand can be reduced by $5.1 \mathrm{kWh} \mathrm{m}^{-2}(55 \%)$ and the heating demand can be reduced by $1.1 \mathrm{kWh} \mathrm{m}^{-2}$ (11\%). For the advanced control strategy, the system was in the insulating state $58 \%$ of the time during the year.

The mean exterior air temperature over $24 \mathrm{~h}$ above which the system is switched from heating to cooling mode has also been optimized for both control strategies. A high switching temperature lowers the heating demand, while a low one favours the cooling demand, as the corresponding operating modes are activated more frequently. A low switching value also lowers the artificial lighting 
Table 4

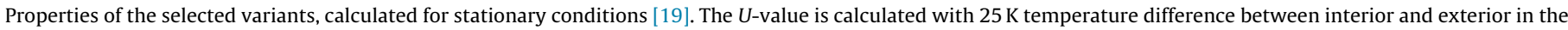

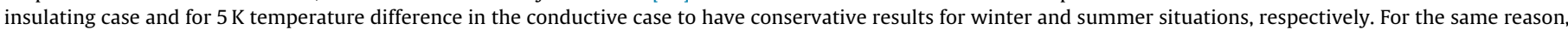
the $g$-value was calculated for a winter case with a $25 \mathrm{~K}$ temperature difference and a direct solar irradiance of $500 \mathrm{~W} \mathrm{~m}^{-2}$ incident on the facade with $0^{\circ}$ incidence angle.

\begin{tabular}{|c|c|c|c|c|c|}
\hline $\begin{array}{l}\text { Application } \\
-\end{array}$ & $\begin{array}{l}\text { Front cover } \\
-\end{array}$ & $\begin{array}{l}\text { Back cover } \\
\text { - }\end{array}$ & 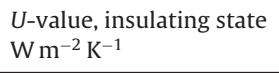 & 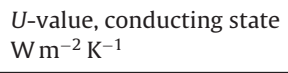 & $\begin{array}{l}\text { g-Value, conducting state } \\
-\end{array}$ \\
\hline Wall & Solar glass & Black paint & 0.14 & 2.76 & 0.49 \\
\hline Window & Solar glass & Solar glass & 0.14 & 2.70 & 0.84 \\
\hline
\end{tabular}

\begin{tabular}{|l}
$\square$ \\
$\square$ Coating demand \\
$\square$ Artificial lighting demand
\end{tabular}

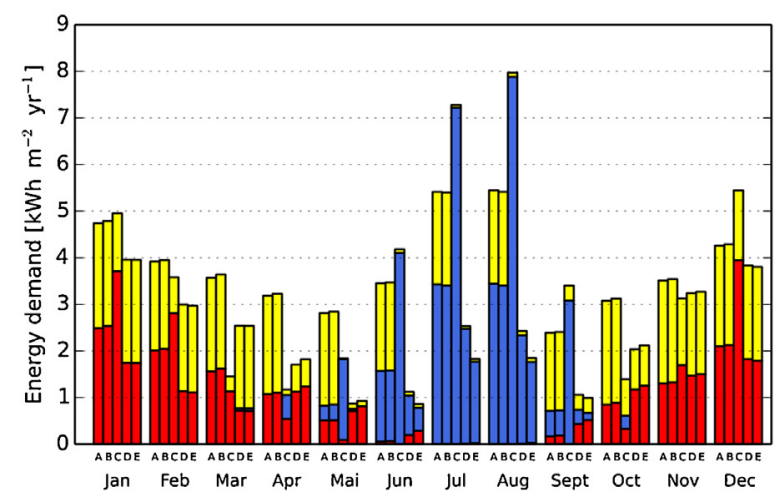

Fig. 11. Building simulation results: monthly energy demand for different variants, for the window application. Cases A, B, C, D and E are respectively the reference case, the "Always down" case, the "Always up" case, the case with the simple control strategy and the case with the advanced control strategy. Results expressed in useful energy.

demand because the heating mode is less frequent. The optimum was found for a switching temperature of $5.2^{\circ} \mathrm{C}$. This value is also the optimum for the advanced control strategy. Also, the irradiance level above which the element is switched has been varied, with a value of $150 \mathrm{~W} \mathrm{~m}^{-2}$ chosen for this simple control strategy. This optimization process is detailed in [19].

In Fig. 11, monthly results are shown. While the simple and advanced control strategies have a similar performance during the heating period and in mid-season, the advanced control strategy performs much better during the cooling period due to a larger reduction of the cooling load. It is interesting to note that the "Always up" variant is competitive in winter despite the higher $U$-value, due to the high solar gains.

\subsection{Wall application}

Similarly, the wall variant was simulated, with the element replacing the external insulation on the lower and upper thirds of the south external facade. The results can be seen in Fig. 12.

The difference between the reference case and the "Always down" case is explained by the frame of the switchable element: since no constructions details of the frame where available, the $U$ value of the frame was assumed to be equal to $0.85 \mathrm{~W} \mathrm{~m}^{-2} \mathrm{~K}^{-1}$, corresponding for example to an aluminium/wood window frame. After weighting with their respective areas, the $U$-value of the total element area (with frame) in insulating state is $0.23 \mathrm{~W} \mathrm{~m}^{-2} \mathrm{~K}^{-1}$, while the reference external facade has an $U$-value of $0.15 \mathrm{~W} \mathrm{~m}^{-2} \mathrm{~K}^{-1}$. Consequently, when the external insulation is replaced by the switchable element in the "Always down" position, the heating demand increases because of the frame/edge-effects while the cooling demand decreases slightly.

When the element is always in the conducting state (up), it acts as a Trombe wall: the solar energy absorbed at the absorb-

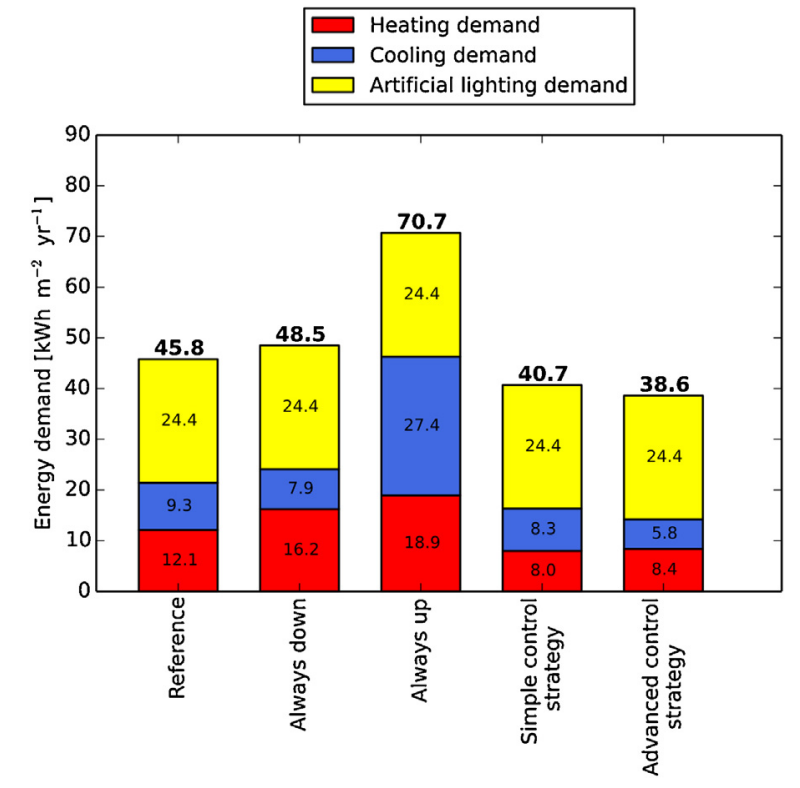

Fig. 12. Building simulation results: wall application. Results expressed in useful energy.

ing black surface of the wall external surface increases the cooling demand significantly. The additional heat gains in winter are not outweighed by the additional heat loss due to the higher $U$-value of the element in the conducting state, with a $20 \mathrm{~cm}$ air cavity allowing enclosed convection [19].

With the simple control strategy, compared to the reference, the sum of heating and cooling demands is reduced by $24 \%$ $\left(5.1 \mathrm{kWh} \mathrm{m}^{-2}\right)$ : the cooling demand is reduced by $1.0 \mathrm{kWh} \mathrm{m}^{-2}$ $(11 \%)$ and the heating demand by $4.1 \mathrm{kWh} \mathrm{m}^{-2}$ (34\%). However, if we compare the element switched according to the simple control strategy to the case of the element always in the insulating case ("Always down"), it can be observed that the heating demand can be reduced by about half. However, the cooling energy demand increases slightly, which is due to the optimization of the switching temperature between the heating and cooling modes. This optimization aims to reduce the total heating and cooling demand [19].

The advanced control strategy produces the best results with a reduction of the sum of heating and cooling demands by $34 \%$ ( $7.2 \mathrm{kWh} \mathrm{m}^{-2}$ ) compared to the reference: the cooling demand is reduced by $3.5 \mathrm{kWh} \mathrm{m}^{-2}$ (38\%) while the heating demand is reduced by $3.7 \mathrm{kWh} \mathrm{m}^{-2}$ (31\%) compared to the reference. To assess the true potential of switching the insulation, the variant with the advanced control strategy is compared to the "Always down" case: a reduction by $41 \%\left(9.9 \mathrm{kWh} \mathrm{m}^{-2}\right)$ of the sum of the heating and cooling demand is then achieved.

For both control strategies, the 24-h mean outdoor temperature to govern switching between heating and cooling mode has again been optimized. The optimum is higher than for the window element and was found to be $9.6^{\circ} \mathrm{C}$ for both control strategies. The difference to the window element is that the control strat- 


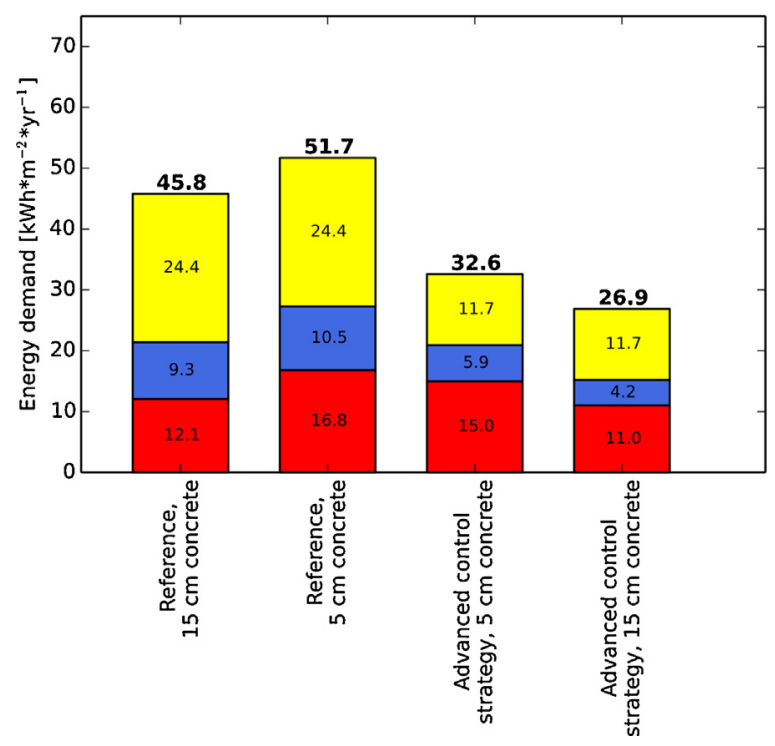

Fig. 13. Building simulation results: influence of the thermal mass on the window variant with advanced control strategy. Results expressed in useful energy.

egy has no influence on the artificial lighting demand here. Near this optimum, the slight increase in the cooling demand is overcompensated by the significant decrease in the heating demand. For the simple control strategy, the irradiance limit has also been optimized [19].

To underline the impact of the frame on performance, the "window" frame of the wall element, with an $U_{f}$-value of $0.85 \mathrm{~W} \mathrm{~m}^{-2} \mathrm{~K}^{-1}$, is insulated at the same level as the opaque walls of the reference $\left(U=0.15 \mathrm{~W} \mathrm{~m}^{-2} \mathrm{~K}^{-1}\right)$. Then, the reduction of the sum of heating and cooling demand compared to the reference increases to $36 \%\left(7.7 \mathrm{kWh} \mathrm{m}^{-2}\right)$ instead of $34 \%$.

\subsection{Influence of thermal mass}

The impact of the thermal mass on the performance of the switchable insulation was also investigated. The well-insulated reference building has $15 \mathrm{~cm}$ concrete on all internal and external walls. The influence of a lower thermal mass on the variant with the window element and the advanced control strategy is shown in Fig. 13.

For the reference, the same room with a lower thermal mass has a higher energy demand: thermal mass absorbs the peaks of room loads, tempering overheating in summer and helping to store solar gains during winter days.

Concerning the variants with switchable insulation, the thermal mass has an important impact on the performance: for the case with $15 \mathrm{~cm}$ concrete, the sum of the heating and cooling demand was reduced by $29 \%\left(6.2 \mathrm{kWh} \mathrm{m}^{-2}\right)$ compared to the reference, as shown previously. With $5 \mathrm{~cm}$ concrete, the reduction due to the switchable insulation drops to $23 \%\left(6.4 \mathrm{kWh} \mathrm{m}^{-2}\right)$, compared to the reference with only $5 \mathrm{~cm}$ concrete: in winter the thermal mass allows the solar gains to be stored when the element is in the conducting state, while during the cooling periods the thermal mass cools down during night-time and dampen the effect of internal gains and solar radiation during daytime.

For the wall variant, the conclusion is similar: the reduction of heating and cooling demand drops from $31 \%\left(6.7 \mathrm{kWh} \mathrm{m}^{-2}\right)$ for the $15 \mathrm{~cm}$ concrete case to $15 \%\left(4.2 \mathrm{kWh} \mathrm{m}^{-2}\right)$ for the case with $5 \mathrm{~cm}$ concrete. It has also been checked that the optimal switching temperature for the control strategies did not change with a different level of thermal mass.

\subsection{Influence of the orientation}

Finally, the potential of the switchable insulation was also investigated for other orientations than the original south orientation, with the advanced control strategy. The whole room was rotated so that the orientation of the external facade changed from south to west, north and east.

The reference building has an external blind over the triple glazing window in the central area. The blinds goes down when the total irradiance exceeds $150 \mathrm{~W} \mathrm{~m}^{-2}$, in order to prevent glare and reduce the cooling load during the cooling period. This control strategy is the same for all four orientations, and the consequence is that for example for the south facade, the blind is down for $1859 \mathrm{~h}$ over the year while for the north facade it is only down for $534 \mathrm{~h}$. The consequence is that for the reference building the solar gains to the room are quite similar for the four orientations, leading to very similar energy demands.

For the window variant, the greatest reduction in the sum of the heating and cooling demands is for the south facade, with $29 \%\left(6.2 \mathrm{kWh} \mathrm{m}^{-2}\right)$ reduction compared to the reference. The west, north and east facade show reductions of respectively $17 \%$ (3.8 $\left.\mathrm{kWh} \mathrm{m}^{-2}\right), 8 \%\left(1.7 \mathrm{kWh} \mathrm{m}^{-2}\right)$ and $19 \%\left(4.3 \mathrm{kWh} \mathrm{m}^{-2}\right)$ : while the reduction of the cooling demand is still important (but lower than for the south orientation), there is no reduction of the heating demand: one reason is the lower level of solar irradiance incident at the facade for other orientations, with smaller solar gains during the heating period. The other reason is due to the optimization of the switching temperature between the heating and cooling modes, which minimizes the sum of heating, cooling and lighting demands. If the optimization was based on heating and cooling only, a higher switching temperature would be taken and a larger reduction of heating and cooling could be achieved.

For the wall variant, the switchable element does not affect the artificial lighting. For the south orientation, it was shown in the previous results that a reduction of the sum of the heating and cooling demand by $31 \%\left(6.7 \mathrm{kWh} \mathrm{m}^{-2}\right)$ compared to the reference could be achieved. For other orientations, the reduction is smaller. For the west and east orientations, the reduction of the sum of the heating and cooling demand is $13 \%\left(2.8 \mathrm{kWh} \mathrm{m}^{-2}\right)$ and $12 \%$ $\left(2.6 \mathrm{kWh} \mathrm{m}^{-2}\right)$, respectively, while there is no improvement for the north orientation: here, the reduction of the cooling and heating demand is compensated by the energy flowing through the frame of the element. Relative to the variant with the element always in an insulating state, the reduction is again higher, since the frame with low insulation is then present in both cases. For the wall variant, it is interesting to note that the optimal switching temperature between the heating and cooling modes (average external temperature over $24 \mathrm{~h}$ ) changes significantly for other orientations: for the west and north orientations, the optimum switching temperature is $10.0^{\circ} \mathrm{C}$ and $12.6^{\circ} \mathrm{C}$, respectively, instead of $9.6^{\circ} \mathrm{C}$ for the south and east orientations.

\subsection{Calculated element versus measured one}

The previous results have been simulated using the ISO 15099 standard included in EnergyPlus. However, during the comparison between the ISO 15099 model and the experimental measurement of a prototype, it has been shown that the prototype has a higher $U$-value than predicted by the model in the insulating state due to edge effects. In this section, the impact of this difference on the building simulation results is discussed. From the five $U$-value measurements presented in this paper, the case with the high- 
est $U$-value has been chosen ("worst case"), with an $U$-value of $0.45 \mathrm{~W} \mathrm{~m}^{-2} \mathrm{~K}^{-1}$. Since the $U$-value measurement was performed with 11 cavities of about $9 \mathrm{~mm}$ thickness, the equivalent thermal conductivity of the element has been calculated. This thermal conductivity was then used to calculate the thermal resistance of an equivalent element of $20 \mathrm{~cm}$ overall thickness, which has been implemented in the building simulation model. The $U$-value of this $20 \mathrm{~cm}$ thick element is then $0.22 \mathrm{~W} \mathrm{~m}^{-2} \mathrm{~K}^{-1}$ to be compared to the value of $0.14 \mathrm{~W} \mathrm{~m}^{-2} \mathrm{~K}^{-1}$ of the theoretical calculation.

For the window element, replacing the theoretical $U$-values with this equivalent measured value leads to a very small increase of the heating demand from $11.0 \mathrm{kWh} \mathrm{m}^{-2}$ to $11.2 \mathrm{kWh} \mathrm{m}^{-2}$ in the variant with the advanced control strategy. For the wall element, the heating demand increases from $8.7 \mathrm{kWh} \mathrm{m}^{-2}$ to $9.1 \mathrm{kWh} \mathrm{m}^{-2}$. The cooling demand remained unchanged for both the wall and window configurations. With the measured $U$-values, the performance of the switchable insulation is not affected in a significant way. The reason is that this higher $U$-value is compensated by the solar gains achieved during the heating period with the switching process.

\section{Conclusion}

In this publication, a new facade element with switchable thermal and optical properties has been introduced. A first prototype has been measured, showing $U$-values of about $0.40 \mathrm{~W} \mathrm{~m}^{-2} \mathrm{~K}^{-1}$ in the insulating state, which is higher than calculated with the ISO 15099 standard. The difference is most probably due to air leakage at the connection with the frame. A preliminary study using the ISO 15099 in a stationary calculation showed that $U$-values could be switched from a (theoretical) low value of $0.14 \mathrm{~W} \mathrm{~m}^{-2} \mathrm{~K}^{-1}$ to a high value of about $2.7 \mathrm{~W} \mathrm{~m}^{-2} \mathrm{~K}^{-1}$ when switching from the insulating to the conducting state. In the same time, the $g$-value is switched from zero to 0.49 or 0.84 in the wall and window applications, respectively.

The potential of the new concept has then been investigated with building simulations for an office space in a continental European climate. A well-insulated building was simulated and two different control strategies where developed. The new concept was applied as a wall application and as a window application. Simulation results showed that for the window configuration, a reduction of the sum of the heating and cooling demands by $29 \%$ $\left(6.2 \mathrm{kWh} \mathrm{m}^{-2}\right)$ could be achieved with the advanced control strategy that has been developed: the cooling demand can be reduced by $55 \%$ and the heating demand can be reduced by $11 \%$. As an opaque surface is replaced by a transparent (switchable) element, the artificial lighting demand is reduced by $52 \%\left(12.7 \mathrm{kWh} \mathrm{m}^{-2}\right)$. For the wall element, a reduction of the sum of heating and cooling demands by $31 \%\left(6.7 \mathrm{kWh} \mathrm{m}^{-2}\right)$ could be achieved compared to the reference: the cooling demand is reduced by $35 \%$ and the heating demand by $28 \%$ compared to the reference. A frame $U$-value of $0.85 \mathrm{~W} \mathrm{~m}^{-2} \mathrm{~K}^{-1}$ was assumed, corresponding to a high performance window frame, which decreases slightly the performance of the element in the insulating state when compared to the $0.15 \mathrm{~W} \mathrm{~m}^{-2} \mathrm{~K}^{-1}$ opaque wall of the reference. With a $20 \mathrm{~cm}$ element thickness, a lower $U$ value could probably be achieved for the frame. Consequently, the thickness of the centre of glazing part could be reduced while still achieving the same overall $U$-value (frame + center of glazing) in the insulating and conducting state (see also Fig. 9) and consequently the same performance. The "higher" $U$-value of the frame assumed in this contribution could for example represent edge effects due to the mechanism at the top, but was chosen arbitrarily since no details were available at this stage.

The influence of thermal mass is very high on the reduction of heating and cooling demands: for example, in a building with a lower thermal mass, the wall variant with the advanced control strategy would only reduce the heating and cooling demand by $15 \%$ (instead of $31 \%$ ). The best potential was found (for the investigated Stuttgart climate) for a South orientation, with significant solar gains causing cooling loads in summer and possible heat gains in winter. It was also shown that the measured higher $U$-value in the insulating state compared to the calculated one does not affect the performance of the switchable insulation significantly.

One observation is that, even for the south facade, there is often a time shift between the available benefits of the switchable insulation and when they are needed: for example, in winter, the most sunny days also have the lowest heating demand. The solar gains from the best performing orientations could then be used for less well-performing rooms with other orientations, for example by using mechanized ventilation between rooms. Another point of improvement would be to optimize the period over which the external temperature is integrated (currently $24 \mathrm{~h}$ ) to switch between the heating and cooling modes to fit better to the climate and the building thermal mass.

\section{Acknowledgements}

The switchable insulation concept behind this article was invented by Mr. Sergej Kvasnin, owner of the company I[n]solation UG. The authors want to thank Mr. Kvasnin for the constructive discussions. Special thanks are also extended to the Rud. Otto Meyer-Umwelt-Stiftung for financing the research leading to this publication.

The authors acknowledge the financial contribution of the Arconic Foundation.

\section{References}

[1] Décret n ${ }^{\circ}$ 2012-1530 du 28 décembre 2012 relatif aux caractéristiques thermiques et à la performance énergétique des constructions de bâtiments: RT2012 (2012).

[2] Passivhaus Institut, Anforderungen und Prüfverfahren zur energetischen und schalltechnischen Beurteilung von Passivhaus-Lüftungsgeräten $<600 \mathrm{~m}^{3} / \mathrm{h}$ für die Zertifizierung als Passivhaus geeignete Komponente (2009).

[3] Verein MINERGIE, Reglement zur Nutzung der Qualitätsmarke MINERGIE ${ }^{\circledR}$ (2014).

[4] T. Berger, C. Amann, H. Formayer, A. Korjenic, B. Pospichal, C. Neururer, R. Smutny, Impacts of external insulation and reduced internal heat loads upon energy demand of offices in the context of climate change in Vienna, Austria, J. Build. Eng. 5 (2016) 86-95, http://dx.doi.org/10.1016/j.jobe.2015.11.005.

[5] E. Mlecnik, T. Schütze, S. Jansen, G. de Vries, H.J. Visscher, A. van Hal, End-user experiences in nearly zero-energy houses, Energy Build. 49 (2012) 471-478, http://dx.doi.org/10.1016/j.enbuild.2012.02.045.

[6] R.S. McLeod, C.J. Hopfe, A. Kwan, An investigation into future performance and overheating risks in Passivhaus dwellings, Build. Environ. 70 (2013) 189-209, http://dx.doi.org/10.1016/j.buildenv.2013.08.024.

[7] T.S. Larsen, R.L. Jensen, Comparison of measured and calculated values for the indoor environment in one of the first Danish passive houses, in: Proceedings of Building Simulation 2011: 12th Conference of International Building Performance Simulation Association, Sydney, 14-16 November, 2011.

[8] T.E. Kuhn, Solar control: a general evaluation method for facades with Venetian blinds or other solar control systems, Energy Build. 38 (6) (2006) 648-660, http://dx.doi.org/10.1016/j.enbuild.2005.10.002.

[9] H.R. Wilson, Solar control coatings for windows, in: K. Grassie, E. Teuckhoff, G. Wegner, J. Hausselt, H. Hanselka (Eds.), Functional Materials, vol. 13, 2006.

[10] M.S. Sodha, J.K. Nayak, N.K. Bansal, I.C. Goyal, Thermal performance of a solarium with removable insulation, Build. Environ. 17 (1) (1982) 23-32, http://dx.doi.org/10.1016/0360-1323(82)90006-3.

[11] R. Leppkes, H. Olbrich, Polystyrol-Schaumstoffkugeln für die variable Wärmedämmung und Beschattung von transparenten Gebäudeteilen, patent DE 000003730023C2 (08.09.1987).

[12] F. Stazi, A. Vegliò, C. Di Perna, P. Munafò, Retrofitting using a dynamic envelope to ensure thermal comfort, energy savings and low environmental impact in Mediterranean climates, Energy Buildings 54 (2012) 350-362, http://dx.doi.org/10.1016/j.enbuild.2012.07.020.

[13] M. Kimber, W.W. Clark, L. Schaefer, Conceptual analysis and design of a partitioned multifunctional smart insulation, Appl. Energy 114 (2014) 310-319, http://dx.doi.org/10.1016/j.apenergy.2013.09.067.

[14] S. Kvasnin, lsolationsvorrichtung für Fenster, patent DE 102013001176A1 (24.01.2013).

[15] S. Kvasnin, Isolationsvorrichtung für Fenster oder Fassaden, patent DE 202014000533U1 (23.01.2014). 
[16] R. Caps, J. Hetfleisch, J. Fricke, Vakuumwärmedämmpanel, patent DE 19647 567 C 2 (18.11.1996).

[17] A. Berge, C.-E. Hagentoft, P. Wahlgren, B. Adl-Zarrabi, Effect from a variable $U$-value in adaptive building components with controlled internal air pressure, Energy Procedia 78 (2015) 376-381, http://dx.doi.org/10.1016/j. egypro.2015.11.677

[18] T. Pflug, T.E. Kuhn, R. Nörenberg, A. Glück, N. Nestle, C. Maurer, Closed translucent façade elements with switchable $U$-value - a novel option for energy management via the facade, Energy Build. 86 (2015) 66-73, http://dx. doi.org/10.1016/j.enbuild.2014.09.082.

[19] T. Pflug, Development, characterization and evaluation of switchable facade elements (Ph.D. thesis), Université de Strasbourg, Laboratoire ICube, 2016 http://www.theses.fr/en/2016STRAD017.

[20] ISO 8302:1991: Thermal insulation - Determination of steady-state thermal resistance and related properties - Guarded hot plate apparatus, Technical Committee ISO/TC 163 (1991).

[21] EN 410:2011: Glass in building - Determination of luminous and solar characteristics of glazing, European Committee for Standardization (2011).

[22] ISO 15099:2003: Thermal performance of windows, doors and shading devices - Detailed calculations, Technical Committee ISO/TC 163 (2003).

[23] D.B. Crawley, L.K. Lawrie, F.C. Winkelmann, W.F. Buhl, Y. Huang, C.O. Pedersen, R.K. Strand, R.J. Liesen, D.E. Fisher, M.J. Witte, J. Glazer, Energyplus: Creating a new-generation building energy simulation program, Energy Build. 33 (4) (2001) 319-331, http://dx.doi.org/10.1016/S0378-7788(00)00114-6.

[24] J.R. Howell, R. Siegel, M.P. Mengüç, Thermal Radiation Heat Transfer, fifth ed. CRC Press, Boca Raton, FL, 2011.
[25] C. Braesch, Modeling, validation and simulation of a ventilated window (Diploma thesis) (confidential until 2020), INSA de Strasbourg, Strasbourg, 2015 http://eprints2.insa-strasbourg.fr/1932/.

[26] P.G. Ellis, Development and validation of the unvented Trombe wall model in EnergyPlus (Master thesis), Graduate College of the University of Illinois at Urbana-Champaign, 2003.

[27] J.L. Wright, A correlation to quantify convective heat transfer between vertical window glazings, ASHRAE Trans. 102 (1) (1996).

[28] ISO 7730:2005: Ergonomics of the thermal environment - analytical determination and interpretation of thermal comfort using calculation of the PMV and PPD indices and local thermal comfort criteria, International Organization for Standardization (2005).

[29] DIN V 18599-10:2007: Energy efficiency of buildings - Calculation of the net, final and primary energy demand for heating, cooling, ventilation, domestic hot water and lighting - Part 10: Boundary conditions of use, climatic data, DIN Deutsches Institut für Normung (2007).

[30] T. Kuhn, K. Fath, C. Bales, R. Nouvel, R. Fedrizzi, Project INSPIRE, Deliverable 2.3 RES availability survey and boundary conditions for simulations, 2014.

[31] Lawrence Berkeley National Laboratory, WINDOW 7.2, https://windows.lbl. gov/software/window/window.html (2015).

[32] DIN EN 673:2011-04: Glass in building - Determination of thermal transmittance ( $U$-value ) - Calculation method; German version, DIN Deutsches Institut für Normung (2011).

[33] PassivHaus Institute, Passive house planning package phpp, 2015 http:// passivehouse.com/04_phpp/04_phpp.htm\#PH9. 